\title{
Antimicrobial activity of a quinuclidine-based FtsZ inhibitor and its synergistic potential with $\beta$-lactam antibiotics
}

\author{
Fung-Yi Chan, Ning Sun, Yun-Chung Leung and Kwok-Yin Wong
}

Filamenting temperature-sensitive mutant $Z$ (FtsZ) is an essential cell division protein that cooperates in the formation of the cytokinetic Z-ring in most bacteria and has thus been recognized as a promising antimicrobial drug target. We have recently used a structure-based virtual screening approach to identify pyrimidine-linked quinuclidines as a novel class of FtsZ inhibitors. In this study, we further investigated the antibacterial properties of one of the most potent compounds (quinuclidine 1 ) and its synergistic activity with $\beta$-lactam antibiotics. Susceptibility results showed that quinuclidine 1 was active against multiple antibiotic-resistant bacterial strains including methicillin-resistant Staphylococcus aureus and vancomycin-resistant Enterococcus faecium with minimal inhibitory concentrations of $24 \mu \mathrm{g} \mathrm{ml}-1$. When quinuclidine 1 was combined with $\beta$-lactam antibiotics, synergistic antimicrobial activities against antibiotic-resistant strains of $S$. aureus were found. Further in vitro studies suggest that prevention of FtsZ protofilament formation by quinuclidine 1 impairs the formation of Z-ring, and thus inhibits bacterial division. These findings open a new approach for development of quinuclidine-based FtsZ inhibitors into potent antimicrobial agents.

The Journal of Antibiotics (2015) 68, 253-258; doi:10.1038/ja.2014.140; published online 8 October 2014

\section{INTRODUCTION}

The treatment of bacterial infections has been a clinical challenge worldwide because of the limited number of potent antibacterial therapies against antibiotic-resistant bacteria such as methicillinresistant Staphylococcus aureus (MRSA) and vancomycin-resistant Enterococcus faecium. ${ }^{1}$ Therefore, new antimicrobial agents with innovative mechanisms of action against antibiotic-resistant bacteria are urgently needed. ${ }^{2,3}$ Combining new compounds with existing antibacterial drugs is an alternative approach to treat bacterial infections. Combination therapies exploring the synergistic effects of compounds with different modes of action have been widely used to treat infectious diseases. ${ }^{4}$ For example, $\beta$-lactamase inhibitors such as clavulanic acid, sulbactam and tazobactam have been successfully combined with $\beta$-lactam antibiotics to treat Gram-negative drugresistant bacterial infections. ${ }^{5}$

Filamenting temperature-sensitive mutant Z (FtsZ), a prokaryotic homolog of mammalian $\beta$-tubulin, ${ }^{6}$ is a self-activating guanosine triphosphatase (GTPase) that polymerizes into a highly dynamic cytoskeleton Z-ring at the site of septum formation.,8 Given the essential role of FtsZ in the recruitment of downstream proteins for completion of bacterial cell division, FtsZ is an attractive target for the development of new antibacterial agents that has yet to be developed clinically. ${ }^{9-12}$ A number of FtsZ inhibitors have been reported to impair the bacterial cell division, such as the small-molecule
PC190723 that exhibits in vivo activity in a murine infection model system and restores the susceptibility of MRSA to $\beta$-lactams. ${ }^{9-17}$ A recent report indicated that genetic depletion of FtsZ can cause the delocalization of penicillin-binding protein 2, the target of $\beta$-lactam antibiotics, from the septum in S. aureus, resulting in the impairment of the assembly of bacterial cell wall. ${ }^{18}$

Our previous results from virtual screening combined with biological evaluations led to the identification of a new class of quinuclidine-based FtsZ inhibitors. One of the most potent compounds, (5-(((( (2R,4S,5R)-5-(6-(pentan-3-yl)-2-(pyridin-4-yl)pyrimidin-4-yl)quinuclidin-2-yl)methyl)amino)methyl)furan-2-yl)methanol (quinuclidine 1, Figure 1), inhibited the proliferation of bacterial strains Escherichia coli and S. aureus by inhibiting the GTPase activity of FtsZ. ${ }^{14}$ The purposes of this study were to investigate the underlying mechanisms of antibacterial activity of quinuclidine $\mathbf{1}$ and to explore its synergistic effect in combination with $\beta$-lactam antibiotics against antibiotic-resistant strains of $S$. aureus.

\section{MATERIALS AND METHODS}

Reagents and strains

Quinuclidine 1 was purchased from AnalytiCon Discovery GmbH (Potsdam, Germany). The stock solution was prepared in dimethyl sulfoxide (DMSO). The final percentage of DMSO in the assays was $1 \%(\mathrm{v} / \mathrm{v})$ for all experiments. All other chemicals and reagents were purchased from Sigma-Aldrich 


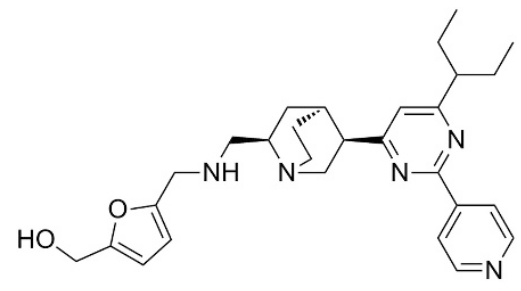

Quinuclidine 1

Figure 1 Structure of quinuclidine 1.

(Shanghai, China), unless otherwise specified. The bacterial strain Bacillus subtilis 168 was available in our laboratory collection. Other bacterial strains were obtained from the American Type Culture Collection (Manassas, VA, USA). E. coli JM109 WM647 was kindly provided by Dr W. Margolin (University of Texas-Houston Medical School, TX, USA).

\section{Determination of MICs and synergistic activity}

Minimum inhibitory concentrations (MICs) for the tested compound and $\beta$-lactam antibiotics were determined using a broth microdilution method in cation-adjusted Mueller-Hinton broth for antibiotic-susceptible strain S. aureus ATCC 29213, ampicillin-resistant S. aureus ATCC 29247, methicillin-resistant S. aureus ATCC BAA- 41 and multidrug-resistant $S$. aureus ATCC BAA- 44 or Mueller-Hinton broth for antibiotic-susceptible strains B. subtilis 168, E. faecalis ATCC 29212, E. faecium ATCC 49624 and E. coli ATCC 25922, and vancomycin-resistant E. faecium ATCC 700221 in accordance with the Clinical and Laboratory Standards Institute standard. ${ }^{19}$ A serial dilution of the compounds were added to the test bacteria $\left(5 \times 10^{5} \mathrm{CFU} \mathrm{m}^{-1}\right)$ in MuellerHinton broth. After $18 \mathrm{~h}$ incubation at $37^{\circ} \mathrm{C}$, the absorbance at $600 \mathrm{~nm}\left(\mathrm{~A}_{600}\right)$ was recorded to calculate the percentage of bacterial cell inhibition with respect to the vehicle (1\% DMSO) using a microplate reader (Bio-Rad Laboratory, Hertfordshire, UK). The MIC values were calculated as the lowest concentration of compounds at which the growth of bacteria was inhibited by $\geqslant 90 \%$. Each assay was performed in triplicates.

The synergistic activity of quinuclidine 1 and $\beta$-lactam antibiotics against ampicillin-resistant S. aureus ATCC 29247 and MRSA ATCC BAA-41 were assessed using a checkerboard broth microdilution method. ${ }^{20}$ The MICs of the tested compound and $\beta$-lactam antibiotics were determined as described above. The checkerboard test was performed in a 96-well microplate containing Mueller-Hinton broth in which a two-dimensional array of serial concentrations of quinuclidine $\mathbf{1}$ and $\beta$-lactam antibiotic is used. For example, synergy between quinuclidine 1 and ampicillin was tested against ampicillin-resistant $S$. aureus in the concentration range of $1.5-24 \mu \mathrm{g} \mathrm{ml}^{-1}(1 / 8 \times \mathrm{MIC}$ to $1 \times \mathrm{MIC})$. For the synergistic tests against MRSA, the concentration ranges of 3-24 $\mu \mathrm{g} \mathrm{ml}^{-1}$ of quinuclidine 1 and $4.5-36 \mu \mathrm{g} \mathrm{ml}^{-1}$ of ampicillin, $16-256 \mu \mathrm{g} \mathrm{ml}^{-1}$ of oxacillin, $128-1024 \mu \mathrm{g} \mathrm{ml}^{-1}$ of methicillin, $2-16 \mu \mathrm{g} \mathrm{ml}^{-1}$ of imipenem, $16-256 \mu \mathrm{g} \mathrm{ml}^{-1}$ of cefoxitin and $2-32 \mu \mathrm{g} \mathrm{ml}^{-1}$ of ceftazidime were used.

The synergistic activity of quinuclidine 1 in combination with $\beta$-lactam antibiotics were then evaluated using a fractional inhibitory concentration index (FICI). The FICI was calculated using the following formula: ${ }^{21}$

$$
\begin{aligned}
\mathrm{FICI}= & \mathrm{FIC}_{\mathrm{cpd} \mathrm{A}}+\mathrm{FIC}_{\mathrm{cpd} \mathrm{B}} \\
= & \left(\mathrm{MIC}_{\mathrm{cpd} \mathrm{A} \text { in combination }} / \mathrm{MIC}_{\mathrm{cpd} \mathrm{A} \text { alone }}\right) \\
& +\left(\mathrm{MIC}_{\mathrm{cpd} \text { B in combination }} / \mathrm{MIC}_{\mathrm{cpd} \text { B alone }}\right) .
\end{aligned}
$$

A FICI $\leqslant 0.5$ was defined as synergistic; a FICI between 0.5 and 1 was defined as partial synergistic; a FICI between 1 and 4 was defined as additive effect or indifferent; and a FICI $>4$ was defined as antagonistic. Experiments from the synergy tests were performed in triplicates.

\section{Determination of frequency of resistance (FOR)}

To determine the FOR for quinuclidine $\mathbf{1}$ alone and in combination with the $\beta$-lactam antibiotic imipenem, MRSA ATCC BAA-41 cells were grown to late-exponential phase $\left(\sim 1 \times 10^{9} \mathrm{CFU} \mathrm{ml}^{-1}\right)$ and spread on brain-heart infusion agar plates containing quinuclidine $\mathbf{1}$ at twofold $\left(48 \mu \mathrm{g} \mathrm{ml}^{-1}\right)$, fourfold $\left(96 \mu \mathrm{g} \mathrm{ml}^{-1}\right)$ and eightfold $\left(192 \mu \mathrm{g} \mathrm{ml}^{-1}\right)$ of the MIC level, or a combination of quinuclidine 1 at twofold the MIC level plus imipenem at the clinical break point MIC $\left(4 \mu \mathrm{g} \mathrm{ml}^{-1}\right)$. To determine the number of viable cells in the starting inoculum, dilutions of the culture were plated on compound-free brain-heart infusion agar plates. Compound plates were incubated for $24 \mathrm{~h}$ to allow resistant mutants to grow. The spontaneous FOR was calculated as the number of resistant colonies on these compound plates divided by the number of CFUs originally plated. Each assay was performed in triplicates.

\section{Expression and purification of $S$. aureus FtsZ}

E. coli BL21(DE3) cells were transformed with the pRSET-A-S vector carrying S. aureus Fts $Z$ with a 6-histidine tag attached at its $\mathrm{N}$ terminus under the control of a T7 promoter. ${ }^{14}$ The transformed E. coli strain was streaked on a nutrient agar plate containing $50 \mu \mathrm{g} \mathrm{ml}^{-1}$ ampicillin and the agar plate was incubated at $37^{\circ} \mathrm{C}$ overnight. A single colony was inoculated into $5 \mathrm{ml}$ of LuriaBertani (LB) medium in the presence of $50 \mu \mathrm{g} \mathrm{ml}^{-1}$ ampicillin, which was then incubated at $37^{\circ} \mathrm{C}$, with shaking at 250 r.p.m. for $16 \mathrm{~h}$. The overnight culture was transferred into a fresh $2 \times$ TY medium ( $16 \mathrm{~g}$ bactotryptone, $10 \mathrm{~g}$ yeast extract, $5 \mathrm{~g} \mathrm{NaCl}$ per litre of water) in a dilution ratio of 1:100 and $50 \mu \mathrm{g} \mathrm{ml}^{-1}$ ampicillin was then added, followed by incubation at $37^{\circ} \mathrm{C}$ with shaking at 250 r.p.m. When the $\mathrm{OD}$ of the culture at $600 \mathrm{~nm}\left(\mathrm{OD}_{600}\right)$ reached 0.8 , protein expression was induced with $0.4 \mathrm{~mm}$ isopropyl- $\beta$-D-thiogalactopyranoside for $4 \mathrm{~h}$. Cells were harvested by centrifugation at 9000 r.p.m. for $20 \mathrm{~min}$ at $4{ }^{\circ} \mathrm{C}$. The cell pellet was resuspended in $20 \mathrm{ml}$ of solubilization buffer (50 mM Tris$\mathrm{HCl}, 150 \mathrm{~mm} \mathrm{NaCl}, 1 \mathrm{~mm}$ PMSF and $1 \mathrm{~mm}$ EDTA, pH 7.4) and then lysed with $1 \mu \mathrm{g} \mathrm{ml}^{-1}$ of lysozyme. The mixture was incubated for $1 \mathrm{~h}$ on ice. The cells were disrupted by sonication and the crude lysate obtained was centrifuged at 13000 r.p.m. for $1 \mathrm{~h}$ at $4^{\circ} \mathrm{C}$. The supernatant containing 6-histidine-tagged S. aureus FtsZ was collected and loaded onto a nickel charged HiTrap chelating column pre-equilibrated with starting buffer ( $20 \mathrm{~mm}$ sodium phosphate buffer, $0.5 \mathrm{M} \mathrm{NaCl}, \mathrm{pH}$ 7.4). The column was then washed with eight column volumes of the starting buffer to remove the unbound proteins, and the histidine-tagged enzyme was eluted by a linear gradient of $0-0.2 \mathrm{M}$ imidazole. Fractions containing S. aureus FtsZ were pooled, buffer-exchanged with $20 \mathrm{~mm}$ $\mathrm{NH}_{4} \mathrm{HCO}_{3}(\mathrm{pH} 8.0)$ at $4{ }^{\circ} \mathrm{C}$, lyophilized and stored at $-20^{\circ} \mathrm{C}$. A stock solution of $S$. aureus FtsZ for the subsequent bioassay was prepared from the lyophilized powder.

\section{Light-scattering assay}

S. aureus FtsZ $(12 \mu \mathrm{M})$ in $50 \mathrm{~mm}$ MOPS buffer ( $\mathrm{pH}$ 6.5) was incubated with vehicle (1\% DMSO) or different concentrations of the tested compound for $10 \mathrm{~min}$ at $25^{\circ} \mathrm{C}$. Then $50 \mathrm{~mm} \mathrm{KCl,}, 10 \mathrm{~mm} \mathrm{MgCl}_{2}$ and $1 \mathrm{~mm}$ GTP were added to the reaction mixture. The rate and extent of polymerization were measured by $90^{\circ}$ light scattering in a thermostatically $\left(37^{\circ} \mathrm{C}\right)$ controlled LS 50B spectrofluorimeter (Perkin Elmer, Waltham, MA, USA) for $1500 \mathrm{~s}$ using excitation and emission wavelength of $600 \mathrm{~nm}$ with slit width of $2 \mathrm{~nm} .{ }^{22}$ Appropriate blanks were subtracted from all experimental data. Reported results are the average of three independent experiments.

\section{Transmission electron microscopy}

S. aureus FtsZ $(12 \mu \mathrm{M})$ was incubated in the absence and in the presence of the tested compound (50-100 $\mu \mathrm{M}$ ) in $50 \mathrm{~mm}$ MOPS (pH 6.5) buffer at $25^{\circ} \mathrm{C}$. After $10 \mathrm{~min}, 50 \mathrm{~mm} \mathrm{KCl}, 5 \mathrm{~mm} \mathrm{MgCl}_{2}$ and $1 \mathrm{~mm}$ GTP were added to the reaction mixtures at $37^{\circ} \mathrm{C}$ for $15 \mathrm{~min}$. Then, $10 \mu \mathrm{l}$ of the sample mixtures were placed on a glow-discharged Formvar carbon-coated copper grid (400 mesh) for $10 \mathrm{~min}$. The grids were subsequently subjected to negative staining using $10 \mu \mathrm{l}$ of $0.5 \%$ phosphotungstic acid for $30 \mathrm{~s}$, air-dried and digital images of the specimen were observed with a transmission electron microscope (JEOL model JEM 2010, Tokyo, Japan) operated at $200 \mathrm{kV}$ and equipped with a Gatan MSC 794 CCD camera. ${ }^{17}$ Three independent experiments were performed for each test.

\section{Bacterial morphology and membrane staining studies}

Visualization of the cell morphology and staining of the cell membrane were performed as previously described. ${ }^{23}$ In brief, the E. coli cells were grown in LB medium. The cultures at an $\mathrm{OD}_{600}$ of 0.01 from an overnight culture were 
grown in the absence or in the presence of $50 \mu \mathrm{m}$ of quinuclidine 1 for $4 \mathrm{~h}$ at $37^{\circ} \mathrm{C}$. The bacterial cells were then harvested and resuspended in phosphatebuffered saline buffer (PBS, pH 7.4) containing $0.25 \%$ agarose. For membrane staining, E. coli cells were stained with a red fluorescent dye FM4-64 (1.6 $\mu \mathrm{M}$, Invitrogen, Eugene, OR, USA) for $15 \mathrm{~min}$ at $37^{\circ} \mathrm{C}$ without shaking before harvested and resuspended in $100 \mu \mathrm{l}$ PBS buffer containing $0.25 \%$ agarose. Ten microliter of sample mixtures were placed on a microscopic slide pre-treated with $0.1 \%(\mathrm{w} / \mathrm{v})$ poly-L-lysine. The bacterial cell morphology was observed under a light phase-contrast microscope Leica DMRB (Leica Microsystems, Wetzlar, Germany) at $\times 40$ magnification. The bacterial cell membrane was visualized using a fluorescence microscope Leica DMRB (Leica Microsystems, Germany) equipped with a $\times 100$ oil immersion magnification with a standard fluorescein isothiocyanate filter set. The images were captured using a Nikon camera. The length of bacterial cells was measured using pre-installed Nikon software. Experiments were performed in triplicates.

\section{Z-ring visualization in $E$. coli cells}

A culture of E. coli JM109 WM647 containing the IPTG-inducible plasmid for the overexpression of green fluorescent protein-tagged FtsZ was grown in LB medium supplemented with $30 \mu \mathrm{g} \mathrm{ml}^{-1}$ of chloramphenicol. After overnight incubation, a sample of the culture was diluted to $1 \%$ in the LB medium containing quinuclidine $1(50 \mu \mathrm{M})$ and $40 \mu \mathrm{M}$ of IPTG. After incubation at $37^{\circ} \mathrm{C}$ for $4 \mathrm{~h}$, the E. coli cells were fixed, harvested and resuspended in PBS buffer containing $0.25 \%$ of agarose. Ten microliter of sample mixture were added to a pre-treated microscopic slide with $0.1 \%(\mathrm{w} / \mathrm{v})$ poly-L-lysine and visualized using a fluorescence microscope at $\times 100$ oil immersion magnification with a standard fluorescein isothiocyanate filter set. One hundred cells were counted to calculate the frequency of occurrence of Z-rings. Experiments were performed in triplicates.

\section{Tubulin polymerization assay}

The effects of quinuclidine 1 on bovine brain tubulin polymerization were tested using the Tubulin Polymerization Assay Kit (Cytoskeleton, Denver, CO, USA). Bovine brain tubulin was used at a final concentration of $2 \mu \mathrm{g} \mathrm{ml}^{-1}$. Quinuclidine $1(600 \mu \mathrm{M})$ was tested in a concentration $>10$ times its $\mathrm{IC}_{50}$ value for S. aureus FtsZ, which has been previously reported. ${ }^{14}$ Paclitaxel $(20 \mu \mathrm{M})$ and vinblastine $(3 \mu \mathrm{M})$ were also included as reference compounds. Fluorescence was measured using a PolarStar Optima microplate reader (BMG Labtech, Offenburg, Germany) at excitation and emission wavelengths of 360 and $450 \mathrm{~nm}$, respectively. Reported results are the average of three independent experiments.

\section{RESULTS}

Quinuclidine 1 (Figure 1) has recently been reported as a new FtsZ inhibitor with antibacterial activity against the Gram-negative bacterial strain E. coli ATCC 25922 and the Gram-positive bacterial strain S. aureus ATCC 29213. ${ }^{14}$ This study aims to further investigate its spectrum of antibacterial activity, as well as the underlying mechanism of action.

\section{Spectrum of antibacterial activity and synergistic effects}

Quinuclidine 1 was tested against an extended panel of clinically relevant bacterial strains. The results are summarized in Table 1. The compound inhibits the growth of antibiotic-susceptible strains (B. subtilis 168, E. faecalis ATCC 29212 and E. faecium ATCC 49624) and antibiotic-resistant strains (ampicillin-resistant $S$. aureus ATCC 29247, methicillin-resistant $S$. aureus ATCC BAA-41, multidrug-resistant $S$. aureus ATCC BAA-44 and vancomycinresistant E. faecium ATCC 700221) with MIC values of $24 \mu \mathrm{g} \mathrm{ml}^{-1}$. This indicates that quinuclidine $\mathbf{1}$ is equally potent against antibioticsusceptible and antibiotic-resistant strains.

To assess the antibacterial activity of quinuclidine $\mathbf{1}$ in combination with the $\beta$-lactam antibiotics against ampicillin-resistant $S$. aureus and MRSA strains, a broth microdilution checkerboard experiment was performed. As shown in Table 2, either compound $\mathbf{1}$ or ampicillin alone showed moderate antibacterial activities against ampicillinresistant $S$. aureus with MIC values of $24 \mu \mathrm{g} \mathrm{ml}^{-1}$. On the opposite, treating the bacteria with a combination of quinuclidine $\mathbf{1}$ and ampicillin apparently improved the antibacterial activities, resulting in a synergistic effect of FICI 0.50. Similar synergistic effects were observed on MRSA by combining quinuclidine 1 with methicillin or imipenem. Combining quinuclidine 1 with other $\beta$-lactam antibiotics showed partial synergistic activity with FICIs of $0.63-0.75$ against MRSA. In these assays, quinuclidine 1 could improve the antibacterial activity of $\beta$-lactam antibiotics against MRSA by reducing the MIC values of ampicillin and oxacillin by fourfold (from 36 to $9 \mu \mathrm{g} \mathrm{ml}^{-1}$ ) and eightfold (from 256 to $32 \mu \mathrm{g} \mathrm{ml}^{-1}$ ), respectively. Improvement in antibacterial activity of cefoxitin (from 256 to $32 \mu \mathrm{g} \mathrm{ml}^{-1}$ ) and ceftazidime (from 32 to $4 \mu \mathrm{g} \mathrm{ml}^{-1}$ ) were also observed in the presence of quinuclidine $\mathbf{1}$.

Table 1 Minimum inhibitory concentration (in $\mu \mathrm{g} \mathrm{ml}^{-1}$ ) of quinuclidine 1 against a panel of bacterial strains

\begin{tabular}{ll}
\hline Organisms $^{\text {a }}$ & MIC \\
\hline B. subtilis 168 & 24 \\
E. coli ATCC 25922 & $36^{\mathrm{b}}$ \\
E. faecium ATCC 49624 & 24 \\
E. faecium ATCC 700221 & 24 \\
E. faecalis ATCC 29212 & 24 \\
S. aureus ATCC 29213 & $24^{\mathrm{b}}$ \\
S. aureus ATCC 29247 & 24 \\
S. aureus ATCC BAA-41 & 24 \\
S. aureus ATCC BAA-44 & 24
\end{tabular}

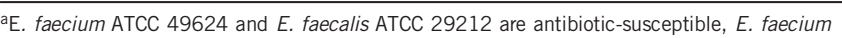
ATCC 700221 is vancomycin-resistant, S. aureus ATCC 29247 is ampicillin-resistant, S. aureus ATCC BAA-41 is methicillin-resistant and $S$. aureus ATCC BAA-44 is multidrug-resistant. ${ }^{\mathrm{D}} \mathrm{MIC}$ values reported in our previous study and shown here for comparison. ${ }^{14}$

Table 2 MIC values (in $\mu \mathrm{g} \mathrm{ml}^{-1}$ ) of quinuclidine 1 combined with $\beta$-lactam antibiotics against antibiotic-resistant strains of $S$. aureus

\begin{tabular}{|c|c|c|c|c|}
\hline Bacterial strain ${ }^{\text {a }}$ & Compound & $\begin{array}{c}\text { Single } \\
\text { compound } \\
\text { MIC }\end{array}$ & $\begin{array}{c}\text { Combination of } 1 \\
\text { and } \beta \text {-lactam } \\
\text { MIC }\end{array}$ & $\mathrm{FICl}^{\mathrm{D}}$ \\
\hline \multirow[t]{2}{*}{ ARSA } & 1 & 24 & 6 & 0.50 \\
\hline & Ampicillin & 24 & 6 & \\
\hline \multirow[t]{2}{*}{ MRSA } & 1 & 24 & 12 & 0.75 \\
\hline & Ampicillin & 36 & 9 & \\
\hline \multirow[t]{2}{*}{ MRSA } & 1 & 24 & 12 & 0.63 \\
\hline & Oxacillin & 256 & 32 & \\
\hline \multirow[t]{2}{*}{ MRSA } & 1 & 24 & 6 & 0.50 \\
\hline & Methicillin & 1024 & 256 & \\
\hline \multirow[t]{2}{*}{ MRSA } & 1 & 24 & 6 & 0.50 \\
\hline & Imipenem & 16 & 4 & \\
\hline \multirow[t]{2}{*}{ MRSA } & 1 & 24 & 12 & 0.63 \\
\hline & Cefoxitin & 256 & 32 & \\
\hline \multirow[t]{2}{*}{ MRSA } & 1 & 24 & 12 & 0.63 \\
\hline & Ceftazidime & 32 & 4 & \\
\hline
\end{tabular}

aARA is ampicillin-resistant $S$. aureus ATCC 29247 and MRSA is methicillin-resistant $S$. aureus ATCC BAA-41.

bThe sum of fractional inhibitory concentration index $(\mathrm{FICl})$ of the two compounds in combination. 


\section{Frequency of resistance}

To assess possible drug resistance induced by quinuclidine 1, MRSA cells were plated on various concentrations of the compound. No single resistant colony was obtained on agar containing quinuclidine $\mathbf{1}$ at twofold, fourfold and eightfold the MIC (48, 96 and $192 \mu \mathrm{g} \mathrm{ml}^{-1}$, respectively), implying a spontaneous FOR of $<1 \times 10^{-9}$. Similar results were observed in the presence of quinuclidine $\mathbf{1}$ combined with imipenem.

Inhibiting the assembly and bundling of FtsZ protofilaments in vitro

Perturbing the polymerization of FtsZ would result in inappropriate FtsZ assembly and disruption of bacterial cell division. The effect of $\mathbf{1}$ on FtsZ polymerization was monitored by measuring the change of light-scattering signal in the presence of the compound. ${ }^{22}$ The lightscattering results showed that the presence of 1 significantly slowed down the assembly of FtsZ monomers (Figure 2a). Moreover, quinuclidine 1 strongly inhibited the polymerization of S. aureus FtsZ in a dose-dependent manner. Compared with the vehicle (1\% DMSO), the polymerization of FtsZ was inhibited by $30 \%$ and $45 \%$ in the presence of $50 \mu \mathrm{m}$ and $100 \mu \mathrm{M}$ of 1 , respectively. The inhibition of FtsZ polymerization could also be observed under a transmission electron microscope. Quinuclidine 1 was found to drastically reduce the size and thickness of the FtsZ polymers and the bundling of the FtsZ protofilaments in a concentration-dependent manner (Figure 2b). At $100 \mu \mathrm{M}$, quinuclidine 1 reduced the thickness of FtsZ protofilaments from $118 \pm 21$ to $60 \pm 12 \mathrm{~nm}$. Only a few straight, short and thin FtsZ filaments were observed in the presence of quinuclidine $\mathbf{1}$.

Inducing filamentation in $E$. coli cells

The influence of quinuclidine $\mathbf{1}$ on the bacterial cell morphology was observed under the microscope to further investigate the underlying

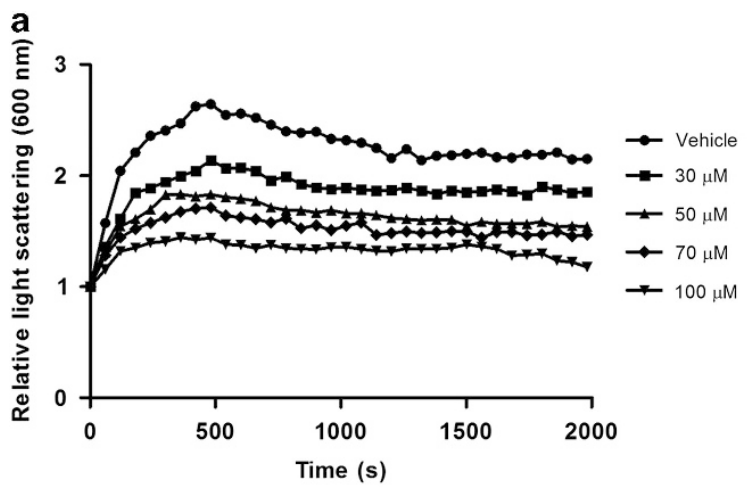

b

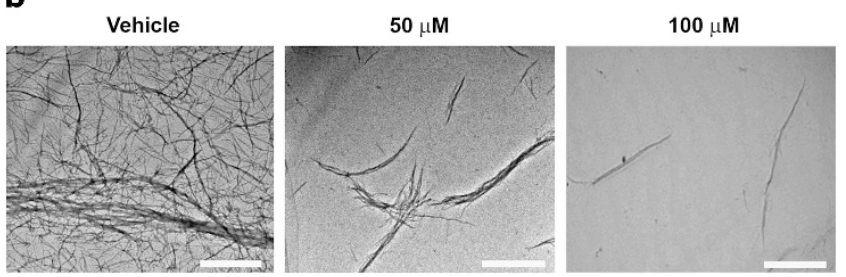

Figure 2 Inhibition of FtsZ assembly. (a) Effect of quinuclidine 1 on the kinetics of $S$. aureus FtsZ polymerization. The experiments were performed in triplicates with symbols representing the mean value $(N=3)$. (b) Electron micrographs of $S$. aureus FtsZ in the absence (vehicle-1\% DMSO) and in the presence of quinuclidine 1 . Scale bar $=2000 \mathrm{~nm}$. The experiments were performed in triplicates. mechanism of its antibacterial activity. In the absence of $\mathbf{1}$, the average length of $E$. coli cells was found to be $2.8 \pm 0.5 \mu \mathrm{m}$. On the other hand, quinuclidine-treated cells were remarkably elongated with lengths in the range of 10-50 $\mu \mathrm{m}$ (Figure 3a). As the perturbation of membrane structure may also lead to bacterial cell lysis and death, the effect of quinuclidine 1 on the bacterial cell membrane was assessed by staining the bacterial cell membrane with the red fluorescent dye FM4-64. In spite of an increased length of the E. coli cells, compound 1 did not induce any detectable perturbation of the cell membrane, as compared with the untreated cells (Figure 3b).

\section{Perturbing the Z-ring formation in E. coli cells}

The effect of quinuclidine $\mathbf{1}$ on cytokinetic Z-ring formation at midcell during bacterial cell division was investigated by fluorescence microscopy (Figure 4). In the absence of quinuclidine 1, E. coli cells had integral Z-rings that consist of green fluorescent protein-tagged FtsZ. On the contrary, green fluorescent protein-tagged FtsZ were found to dispense randomly throughout the elongated E. coli cells in the presence of quinuclidine 1. Furthermore, treatment with quinuclidine 1 markedly reduced the percentage of cells having Z-rings from $93 \%(0 \mu \mathrm{M})$ to $24 \%(50 \mu \mathrm{M})$. The frequency of Z-ring occurrence per unit cell length of $E$. coli cells was found to be $0.38 \pm 0.01$ and $0.05 \pm 0.01$ in the absence (vehicle-1\% DMSO) and in the presence of quinuclidine $\mathbf{1}$, respectively.

\section{Effects on eukaryotic tubulin polymerization}

The effects of quinuclidine $\mathbf{1}$ on bovine brain tubulin polymerization were monitored by fluorescence microscopy after incorporation of a fluorescent reporter 4',6-diamidino-2-phenylindole, dihydrochloride (DAPI) into the microtubules. A known tubulin polymerization enhancer (paclitaxel) and a known inhibitor of tubulin-dependent GTP hydrolysis (vinblastine) were tested as reference compounds in the same assay conditions (Figure 5). In the presence of vinblastine

a

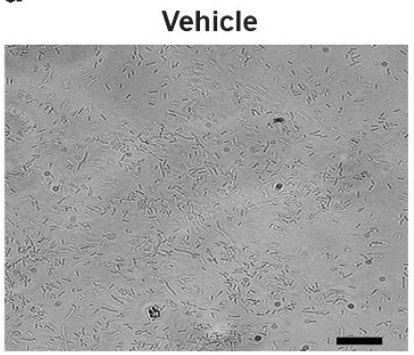

$50 \mu \mathrm{M}$ of quinuclidine 1

b
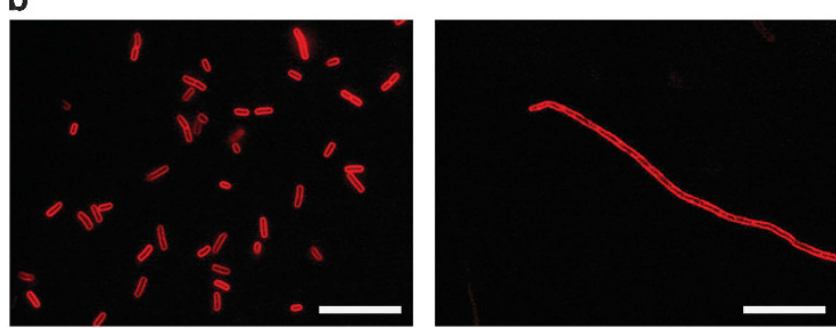

Figure 3 Effects of quinuclidine 1 on the cell morphology and membrane structure of E. coli. (a) E. coli cells were grown in the absence (vehicle-1\% DMSO) or in the presence of quinuclidine 1. (b) Observations after membrane staining with the red fluorescent dye FM 4-64 are shown in the absence (vehicle-1\% DMSO) or in the presence of quinuclidine 1 . Scale bar $=10 \mu \mathrm{m}$. The images are representative of three independent experiments $(N=3)$. 


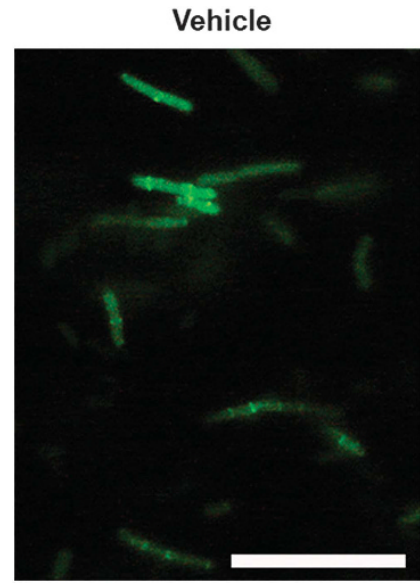

\section{$50 \mu \mathrm{M}$ of quinuclidine 1}

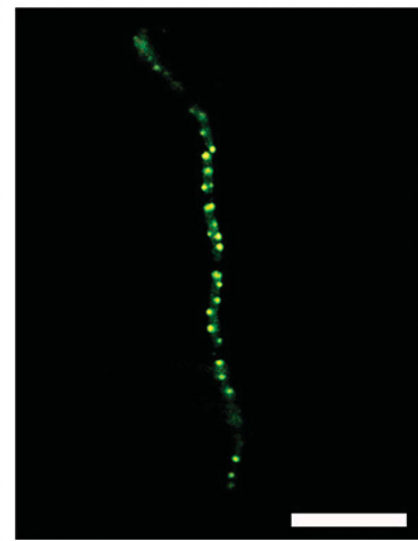

Figure 4 Perturbation of the cytokinetic Z-ring in E. coli cells. Scale $\mathrm{bar}=10 \mu \mathrm{m}$. The images are representative of three independent experiments $(N=3)$

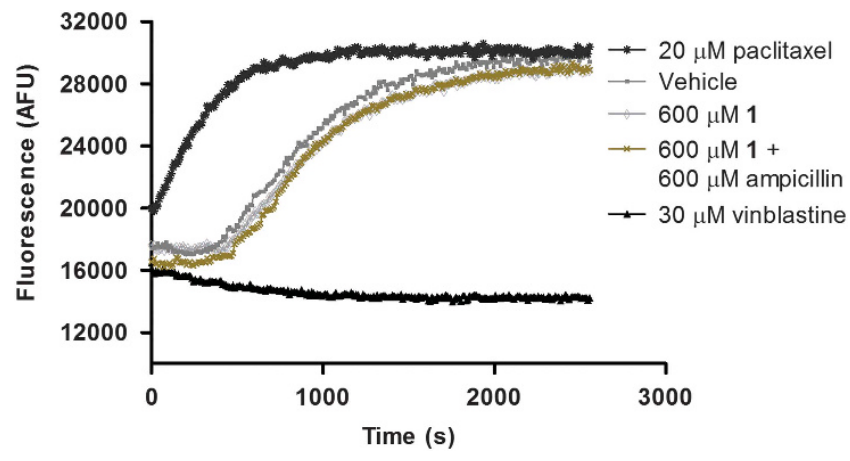

Figure 5 Polymerization of mammalian tubulin. The experiments were performed in triplicates with symbols representing the mean value $(N=3)$

$(30 \mu \mathrm{M})$, the polymerization of mammalian tubulin was completely inhibited. On the opposite, the fluorescence intensity was significantly increased in the presence of paclitaxel $(20 \mu \mathrm{M})$, confirming that the rate of polymerization was significantly enhanced. Quinuclidine 1 $(600 \mu \mathrm{M})$ and a mixture of $1(600 \mu \mathrm{M})$ and ampicillin $(600 \mu \mathrm{M})$ showed similar results to a control experiment with untreated mammalian tubulin, indicating that $\mathbf{1}$ is not an inhibitor of tubulin polymerization.

\section{DISCUSSION}

The results of this study confirm that quinuclidine 1 has broadspectrum antibacterial activity against both Gram-positive and Gramnegative strains through a FtsZ inhibition mechanism. It is well known that the amino-acid sequence of FtsZ is highly conserved in a wide range of bacteria. ${ }^{24}$ Alignment of the GTP-binding sites of FtsZ from various bacterial strains shows differences with pairwise root-meansquare deviation $<0.8 \AA .{ }^{14}$ The broad-spectrum antibacterial activity of quinuclidine 1 may be attributed to the highly conserved GTPbinding site of FtsZ. The susceptibility antibacterial test also showed that there is no difference in the antibacterial potency of quinuclidine 1 against antibiotic-susceptible and antibiotic-resistant strains of E. faecium and S. aureus, thus confirming that the activity of the compound is not affected by common mechanisms of antibiotic resistance. To evaluate the potential use of quinuclidine $\mathbf{1}$ in combination with clinically used $\beta$-lactam drugs, the compound was tested in combination with several $\beta$-lactam antibiotics. This study showed that the activities of two $\beta$-lactams (methicillin and imipenem) against MRSA were greatly enhanced by quinuclidine 1 , while the activity of quinuclidine $\mathbf{1}$ itself was also improved. A previous report by Tan et al. on a small-molecule FtsZ inhibitor from a different class of compounds, PC190723, showed similar synergistic effects with $\beta$-lactam antibiotics against MRSA strains. ${ }^{15}$ However, PC190723 displayed no synergistic activity with non- $\beta$-lactam antibiotics. They hypothesized that the interdependent network of functional interactions between FtsZ and the cell wall biosynthetic proteins (such as the penicillin-binding proteins) might be responsible for the synergy between PC190723 and $\beta$-lactams. Possibly, PC190723-mediated inhibition causes delocalization of FtsZ, which in turn leads to PBP2 delocalization. Consequently, a significantly reduced concentration of the $\beta$-lactam is needed to inhibit the residual functional and correctly localized penicillin-binding protein 2 . The synergistic effects of quinuclidine 1 with $\beta$-lactams probably work through a similar mechanism. However, PC190723 binds to the less conserved C-terminal T7 loop of FtsZ and only works against Gram-positive drugresistant bacteria, ${ }^{25}$ whereas quinuclidine $\mathbf{1}$ binds to the GTP-binding site and exhibits antibacterial activities against both Gram-positive and Gram-negative bacteria.

No spontaneous resistant mutant of MRSA was found in the presence of quinuclidine $\mathbf{1}$ alone or in combination with imipenem. This is different from PC190723 in which a high spontaneous FOR to MRSA has been reported. ${ }^{15}$ As quinuclidine $\mathbf{1}$ is supposed to bind to the GTP-binding site of FtsZ, which is highly conserved compared with the terminal T7 loop. Any mutations of the GTP-binding site in FtsZ might change the protein structure and the GTPase activity, which in turn would seriously affect the function of the protein and therefore could not be compromised. Thus, the failure to identify high-level resistance to quinuclidine $\mathbf{1}$ could be related to the intolerance of structural changes or mutations in the GTPase binding site of FtsZ. Undetectable or very low frequency of spontaneous resistance have also been reported for other GTP-binding site FtsZ inhibitors such as trisubstituted benzimidazole SB-P17G-A20 and PC58538. 26,27

Quinuclidine 1 was found to reduce the light-scattering signal of FtsZ assembly and the bundling of FtsZ protofilaments in a dosedependent manner. The compound impaired the localization of FtsZ into the cytokinetic Z-ring by disruption of the assembly of FtsZ protein. Consequently, a cytokinesis defect was observed in the elongated bacterial cells. Taken together, our findings suggest that quinuclidine $\mathbf{1}$ inhibits bacterial proliferation by inducing bacterial cell filamentation through targeting the FtsZ protein. Our results are in good agreement with findings on FtsZ inhibitors of other chemotypes. ${ }^{17,23}$

In conclusion, quinuclidine 1 exhibits a broad spectrum of antibacterial activity, as well as synergistic effects with $\beta$-lactams against antibiotic-resistant $S$. aureus through the inhibition of FtsZ functional activity. Given the novel molecular scaffold and the encouraging results, quinuclidine derivatives are a promising new class of compounds for further optimization into potent and selective FtsZ-based antibacterial agents.

\section{ACKNOWLEDGEMENTS}

This work was supported by the Research Grants Council (PolyU 5030/11P), the Innovation and Technology Commission and the Hong Kong Polytechnic University. 
1 Rasko, D. A., Sperandio, V. Anti-virulence strategies to combat bacteria-mediated disease. Nat. Rev. Drug Discov. 9, 117-128 (2010).

2 Payne, D. J. Microbiology. Desperately seeking new antibiotics. Science 321, 1644-1645 (2008).

3 Fischbach, M. A., Walsh, C. T. Antibiotics for emerging pathogens. Science 325, 1089-1093 (2009).

4 Desbois, A. P., Lang, S., Gemmell, C. G., Coote, P. J. Surface disinfection properties of the combination of an antimicrobial peptide, ranalexin, with an endopeptidase, lysostaphin, against methicillin-resistant Staphylococcus aureus (MRSA). J. Appl. Microbiol. 108, 723-730 (2010).

5 Drawz, S. M., Bonomo, R. A. Three decades of beta-lactamase inhibitors. Clin Microbiol. Rev. 23, 160-201 (2010).

6 Erickson, H. P. FtsZ, a prokaryotic homolog of tubulin. Cell 80, 367-370 (1995).

$7 \mathrm{Bi}, \mathrm{E}$., Lutkenhaus, J. FtsZ ring structure associated with division in Escherichia coli. Nature 354, 161-164 (1991).

8 Oliva, M. A., Cordell, S. C., Lowe, J. Structural insights into FtsZ protofilament formation. Nat. Struct. Mol. Biol. 11, 1243 (2004)

9 Singh, P., Panda, D. FtsZ inhibition: a promising approach for antistaphylococcal therapy. Drug news perspect. 23, 295-304 (2010).

10 Kapoor, S., Panda, D. Targeting FtsZ for antibacterial therapy: a promising avenue. Expert Opin. Ther. Tar. 13, 1037-1051 (2009).

11 Lock, R. L., Harry, E. J. Cell-division inhibitors: New insights for future antibiotics. Nat Rev. Drug Discov. 7, 324-338 (2008).

12 Awasthi, D., Kumar, K., Ojima, I. Therapeutic potential of FtsZ inhibition: a patent perspective. Expert Opin. Ther. Pat. 21, 657-679 (2011).

13 Schaffner-Barbero, C., Martin-Fontecha, M., Chacon, P., Andreu, J. M. Targeting the assembly of bacterial cell division protein FtsZ with small molecules. ACS Chem. Biol. 7. 269-277 (2012).

14 Chan, F. Y. et al. Identification of a new class of FtsZ inhibitors by structure-based design and in vitro screening. J. Chem. Inf. Model. 53, 2131-2140 (2013).

15 Tan, C. M. et al. Restoring methicillin-resistant Staphylococcus aureus susceptibility to beta-lactam antibiotics. Sci. Transl. Med. 4, 126ra135 (2012).

16 Ruiz-Avila, L. B. et al. Synthetic inhibitors of bacterial cell division targeting the GTPbinding site of FtsZ. ACS Chem. Biol. 8, 2072-2083 (2013).

17 Sun, N. et al. Rational design of berberine-based FtsZ inhibitors with broad-spectrum antibacterial activity. PLoS ONE 9, e97514 (2014).

18 Pinho, M. G., Errington, J. Dispersed mode of Staphylococcus aureus cell wall synthesis in the absence of the division machinery. Mol. Microbiol. 50 871-881 (2003).

19 Clinical and Laboratory Standards Institute. Performance Standards for Antimicrobial Susceptibility Testing; Nineteenth Informational Supplement CLSI document M100S19 CLSI: Wayne, PA, USA, (2009).

20 Lorian, V. in. Antibiotics in Laboratory Medicine 5th edn. Antimicrobial Combinations (eds Pillai S. K., Moellering R. C. J., Eliopoulos G. M.) 365-440 (Lippincott Williams \& Wilkins: Philadelphia, PA, USA, 2005).

21 Odds, F. C. Synergy, antagonism, and what the chequerboard puts between them. $J$. Antimicrob. Chemother. 52, 1 (2003).

22 Beuria, T. K. et al. Glutamate-induced assembly of bacterial cell division protein FtsZ. J. Biol. Chem. 278, 3735-3741 (2003).

23 Beuria, T. K., Santra, M. K., Panda, D. Sanguinarine blocks cytokinesis in bacteria by inhibiting FtsZ assembly and bundling. Biochemistry 44, 16584-16593 (2005).

24 Margolin, W. Themes and variations in prokaryotic cell division. Fems. Microbiol. Rev. 24, 531-548 (2000).

25 Haydon, D. J. et al. An inhibitor of FtsZ with potent and selective anti-staphylococcal activity. Science 321, 1673-1675 (2008).

26 Knudson, S. E. et al. A trisubstituted benzimidazole cell division inhibitor with efficacy against Mycobacterium tuberculosis. PLoS ONE 9, e93953 (2014).

27 Stokes, N. R. et al. Novel inhibitors of bacterial cytokinesis identified by a cell-based antibiotic screening assay. J. Biol. Chem. 280, 39709-39715 (2005). 